\title{
Googlito ergo sum
}

\section{Daniel Schlossberg}

Dr. med., Facharzt Allgemeine Innere Medizin, Mitglied FMH

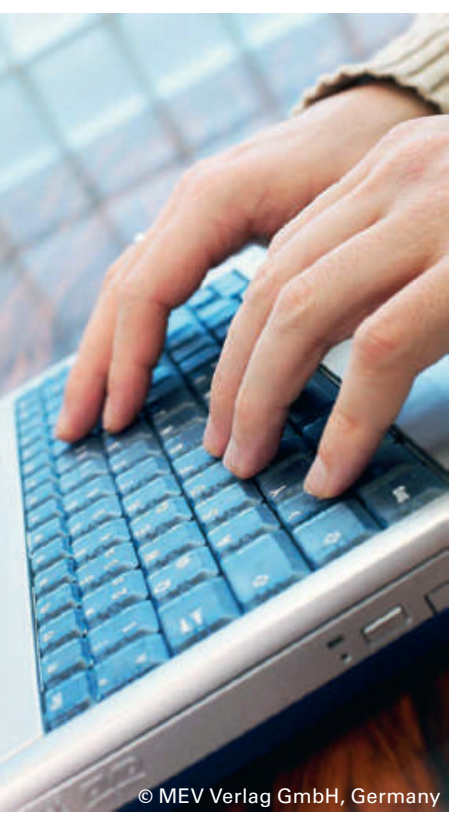

Rückruf aus der Apotheke: Ob man wirklich Azithromycin abgeben soll, der Patient nehme Citalopram!

Oder auf Notfall-Hausbesuch: Die inzwischen nicht mehr vor Ort weilende SpitexPflegefachfrau erklärte den Angehörigen, dass der Patient schon viel zu lang dieses Medikament (Aulin, ein NSAR, das ich persönlich nicht verschreibe) einnehme, sie habe gegoogelt.

Ja, so geht das heute!

Alle fühlen sich berufen, sind vermeintlich sachverständig, verunsichern mit ihrem Halbwissen aus dem Internet und aus irgendwelchen installierten Apps Patienten und Angehörige. Kümmern sich dafür nicht mehr so recht um ihre eigentlichen Aufgaben, die ihnen angedacht waren - ursprünglich einmal.

Leider ist es weit mehr als ein kartesianisches Selbstmissverständnis der Existenz, was ja durchaus noch anginge, was uns heute auf Schritt und Tritt verfolgt. Es ist nämlich die Anmassung derer, die im besagten Gebiet blutige Laien wären, sich zu Laienexperten aufzuschwingen, bloss weil sie ein paar vermeintliche Kenntnisse über das Internet eingeholt haben. Nennen wir diese Menschen der Einfachheit halber «die Internetten». Was sie tun, ist alles andere als nett. Sie diskreditieren mit ihrem Tun bestandene und erfahrene Ärzte, die nicht auf einen Computersturm reagieren, dafür auf einen der Schilddrüse.

Es genügt nicht, zu lesen, dass Sirdalud und Ciproxin ein «No-Go" seien, man muss auch wissen, was dahintersteckt. Nur so kann man Warnungen, die ein Programm von sich gibt, auch richtig interpretieren.

Zugegeben, es ist schwierig genug, in der oft praktizierten und teils erzwungenen Polypharmazie nicht auf Interaktionswarnungen $\mathrm{zu}$ stossen, aber es ist die Erfahrung des Arztes, die hilft, zu entscheiden, was relevant und was im Moment zu vernachlässigen ist. Und wenn wir neue Medikamente, mit denen wir noch nicht genügend Erfahrung haben, einsetzen, wie etwa die Xabane und Gatrane, dann sind wir gezwungen, besonders alert zu sein.

Ja, wir haben es weit gebracht in der modernen Patientenbetreuung, wo uns der Fluch der E-Welt eingeholt hat.
Im Austrittsbericht heisst es: Die Patientin hatte keine Beinödeme, nur hatte die Patientin keine Beine. Sie war beidseitig Oberschenkel-amputiert. Auf den Sachverhalt hingewiesen erwiderte der Verfasser des Austrittsberichts, das sei nun mal so festgehalten und das sei ein Dokument, das man nicht ändern könne. Der völlig falsche Inhalt des Dokuments ist nicht von Belang.

Zuweisungsschreiben werden nicht gelesen, wenn man Glück hat eingescannt und abgelegt, und sind ansonsten halt verloren, was auch nichts macht. Kürzlich wurde eine Patientin hospitalisiert - notabene vom Ambulatorium auf die disziplineigene Bettenstation: Im Bericht war festgehalten, was unter stationären Bedingungen abgeklärt werden sollte. Nach der Entlassung war davon nichts gemacht worden, die Medikation wieder auf jene, die vor zwei Jahren aktuell war, verändert, und bei Nachfrage wusste der Auskunft erteilende Arzt weder, warum dem so war, noch dass ein Auftrag aus dem eigenen Ambulatorium vorgelegen hatte.

Dafür wird regelmässig gegoogelt, Fortbildungen und Rapporte werden abgehalten und zwecks Einhaltung der Work-Life-Balance werden Laptop und Stethoskop, Letzteres dient ausschliesslich noch repräsentativen Zwecken, pünktlich abgelegt.

Auch im Privatleben wird gegoogelt, gewhatsappt und geyoutubet.

Mörderische Spiele werden aus der virtuellen Welt, deren Grenzen sich zunehmend verwischen, immer öfter in die Wirklichkeit transportiert, das geschieht fliessend und gleichsam subkortikal. Moralische Schranken, die in der virtuellen Welt nie bestanden hatten, fallen schleichend in der realen. Wir werden von diesen Prozessen eingeholt, wie der Mordfall von Rupperswil belegt. Und dass dieser Täter zufälligerweise Medizin studiert hat, ist vielleicht gerade typisch. War Descartes' Prämisse "Cogito ergo sum», so wird das gegenwärtige Informationszeitalter von Zahlenalgorithmen geprägt, die an die Stelle von Leibhaftigkeit gerückt sind. So gesehen bekommen jene recht, die sich über "Googlito ergo sum» definieren. Widerwärtig daran ist nur, dass Patienten immer noch als physische Erscheinungen herumgeistern und die so schönen sauberen Abläufe in der Computerwelt durch ihre stinkenden Absonderungen stören. 